\title{
Procedural justice and employee engagement: roles of organizational identification and moral identity centrality
}

DOI:

10.1007/s10551-013-1774-3

Link to publication record in Manchester Research Explorer

\section{Citation for published version (APA):}

$\mathrm{He}, \mathrm{H}$., Zhu, W., \& Zheng, X. (2014). Procedural justice and employee engagement: roles of organizational identification and moral identity centrality. Journal of Business Ethics, 122(4), 681-695.

https://doi.org/10.1007/s10551-013-1774-3

\section{Published in:}

Journal of Business Ethics

\section{Citing this paper}

Please note that where the full-text provided on Manchester Research Explorer is the Author Accepted Manuscript or Proof version this may differ from the final Published version. If citing, it is advised that you check and use the publisher's definitive version.

\section{General rights}

Copyright and moral rights for the publications made accessible in the Research Explorer are retained by the authors and/or other copyright owners and it is a condition of accessing publications that users recognise and abide by the legal requirements associated with these rights.

\section{Takedown policy}

If you believe that this document breaches copyright please refer to the University of Manchester's Takedown Procedures [http://man.ac.uk/04Y6Bo] or contact uml.scholarlycommunications@manchester.ac.uk providing relevant details, so we can investigate your claim.

\section{OPEN ACCESS}




\title{
Procedural Justice and Employee Engagement: Roles of Organizational Identification and Moral Identity Centrality
}

\author{
Hongwei He $\cdot$ Weichun Zhu $\cdot$ Xiaoming Zheng
}

Received: 10 December 2012/ Accepted: 4 June 2013

(C) Springer Science+Business Media Dordrecht 2013

\begin{abstract}
Workplace procedural justice is an important motivator for employee work attitude and performance. This research examines how procedural justice affects employee engagement. We developed three propositions. First, based on the group engagement model, we hypothesized that procedural justice enhances employee engagement through employee organizational identification. Second, employees with stronger moral identity centrality are more likely to be engaged in their jobs. Third, procedural justice compensates for the effect of moral identity centrality on employee engagement. Specifically, when procedural justice is higher, employee moral identity centrality plays a less significant role in employee engagement; whilst when procedural justice is lower, the effect of moral identity centrality on employee engagement is stronger. Research findings based on an employee survey in a leading financial service organization provide support for the above propositions.
\end{abstract}

Keywords Procedure justice - Moral identity · Organizational identification - Employee engagement . Group engagement model

\footnotetext{
H. He ( $\square)$

Strathclyde Business School, University of Strathclyde, Glasgow G4 0QU, UK

e-mail: hongwei.he@strath.ac.uk
}

W. Zhu

Department of Labor Studies and Employment Relations, Pennsylvania State University, University Park, PA 16802, USA

e-mail:wuz13@psu.edu

\section{$X$. Zheng}

School of Economics and Management, Tsinghua University, Beijing 100084, China

e-mail: zhengxm@sem.tsinghua.edu.cn

\section{Introduction}

Understanding how procedural justice impacts employee job-related performance and attitudes is a key management issue that has generated widespread academic attention (e.g., Bernerth and Walker 2012; Colquitt 2001; El Akremi et al. 2010; Fortin and Fellenz 2008; Li and Cropanzano 2009; Walumbwa et al. 2009; Zapata-Phelan et al. 2009). Procedural justice refers to the perceptions an employee holds about the policies and procedures administered by an organization (Konovsky 2000; Loi et al. 2012). In contrast to distributive justice, which focuses on the fairness in the outcomes/distribution of rights and resources, procedural justice concerns the fairness and transparency of the processes of how decisions are made in terms of rewards, promotions, resource allocation, and so on. Procedural justice also differs from interactional justice, which refers to how individual employees are treated with dignity, respect, and with sufficient explanation, normally by their supervisors (Aryee et al. 2004). Procedural justice is a major justice-related factor motivating employee cooperative behavior and enhancing job-related performance (Aryee et al. 2004; Brebels et al. 2011a, b; Cohen-Charash and Spector 2001; Wu and Chaturvedi 2009).

Despite the sizable literature on the impact of procedural justice on employee outcomes, surprisingly, little academic attention has been paid to examining the relationship between procedural justice and an increasingly salient and focal employee outcome (i.e., employee engagement). Employee engagement refers to the simultaneous investment of physical, cognitive, and emotional energy in workrelated performance as a means of self-expression (Kahn 1990, 1992). Employee engagement is an important predictor of employee job performance, both in terms of inrole and extra-role performance (Christian et al. 2011; Ho 
et al. 2011; Rich et al. 2010). Employee engagement differs from and has a stronger performance-enhancing effect than other, similar job-related constructs, such as job involvement, intrinsic motivation, and job satisfaction (Rich et al. 2010). For example, Rich et al. (2010) find that when controlling for job involvement, job satisfaction, and intrinsic motivation, employee engagement has a stronger significant impact on task performance and employee organization citizenship behavior than the above-mentioned variables (i.e., job involvement, job satisfaction, and intrinsic motivation). Yet, the absence of justice could discourage employees from engaging with their jobs because they might believe that the effort invested would not be fairly acknowledged or rewarded by their organization. Therefore, examining how and why procedural justice affects employee engagement is not only of significant theoretical value for both justice and employee engagement scholarship, but also has important practical implications for managing employee engagement in organizations.

Organizations are constantly trying to find solutions to motivate their employees to be more highly engaged in their work (Avery et al. 2007; Cole et al. 2010, 2012). A report published by the Gallup Organization indicated that only a third (33\%) of American employees were 'engaged with their job', while the other two-thirds were either 'not engaged' or 'actively disengaged' with their jobs (Gallup Organization 2010). Similarly, in the United Kingdom, a study (Truss et al. 2006) found that only $30 \%$ of employees in the U.K. are actively engaged with their jobs. Macleod and Clarke (2009), in a report to the U.K. government, also indicated that engagement levels in the U.K. are low. This serious reality poses a significant challenge for both organizational researchers and practitioners on how to enhance employee engagement, which, in turn, is posited to affect organizational performance and outcomes (Harter et al. 2002).

We draw upon the group engagement model to theorize the process of how procedural justice relates to employee engagement. The group engagement model advocates that the way in which a group makes a person thinks and feels about himself/herself affects the individual's behavioral effort toward the group's collective interest (Blader and Tyler 2009; Tyler and Blader 2003). Specifically, the group engagement model argues that procedural justice impacts employee behavior through, at least partially, the process of social identity (Blader and Tyler 2009, p. 447). Therefore, the group engagement model (Blader and Tyler 2009; Restubog et al. 2008; Tyler and Blader 2003) offers valuable insights explaining the phenomenon of procedural justice's effect on employee pro-group behaviors, because procedural justice enhances employee organizational identification (OID). OID, as a central employee social identity at the workplace, refers to the extent to which an employee experiences a sense of oneness with an organization (Ashforth and Mael 1989). Specifically, the group engagement model stresses the impact of procedural justice on OID (Blader and Tyler 2009), which in turn is considered a key antecedent of employee engagement (Luyckx et al. 2010).

Moreover, organizational justice literature has noted the moral relevance and implications of organizational justice and fairness (Brebels et al. 2011a, b; Skarlicki et al. 2008), and has called for more research to integrate moral psychology into the field of inquiry related to organizational justice (Cropanzano et al. 2001, 2003; Rupp and Bell 2010). Indeed, fairness has been identified as a central moral trait that constitutes moral identity (Aquino and Reed 2002). Being fair is a pivotal criterion of ethical leadership behaviors (Brown and Treviño 2006). On the other hand, lack of justice/fairness could lead to harmful and unethical behaviors, such as retaliation (Skarlicki et al. 2008). Accordingly, this research examines the role of a critical identity-related moral construct, that is moral identity centrality, which refers to the extent to which a person defines himself/herself with reference to typical moral traits, such as being caring, fair, hard-working, and helpful (Aquino and Reed 2002). Recent scholarship has called for more research to understand employee behaviors, especially morally relevant behaviors, from a moral agent perspective (see Shao et al. 2008; Trevino et al. forthcoming). Prior research on employee (un)ethical behaviors has been largely focused on situational factors as well as the moral reasoning process. As noted by Shao et al. (2008), from a moral agent perspective, employee moral identity (MI) may play an important role in explaining employee behaviors. Incorporating MI and procedural justice to predict employee behaviors has the advantage of integrating both personal factors and situational factors in explaining employee behaviors. First, MI is one important type of employee identity that may impact employee attitudes and behaviors in organizations (e.g., McFerran et al. 2010; Shao et al. 2008; Skarlicki et al. 2008; Weaver 2006). Second, most previous research on MI mainly focuses on its impact on altruistic (or extra-role) types of behaviors (e.g., Aquino et al. 2009, 2011; Reed et al. 2007; Reynolds and Ceranic 2007; Vitell et al. 2009; Winterich et al. 2009). We believe it is also of importance to assess how MI influences employees' 'in-role' behaviors and performance in a work setting.

We also examine the interactional effects between MI centrality and procedural justice on employee engagement because doing so enables the research to test the personsituation framework, especially the strong-situation hypothesis (e.g., Cooper and Withey 2009; Meyer et al. 2010; Mischel 1977). A situation is considered strong when 
the situation is unambiguous and provides clear guidelines for employee behavior (Mischel 1977; Shane et al. 1996). This hypothesis states that in a strong situation, personal differences (i.e., MI centrality in the current research) play a less significant role in determining behavior. Thus we expect that MI centrality has a weaker effect on employee engagement when perceived procedural justice is higher. Figure 1 illustrates our proposed conceptual framework.

In brief, this research makes a number of contributions to the literature. First, this research asserts that procedural justice moderates the impact of MI centrality on employee engagement. Second, this research also posits that procedural justice enhances employee OID, which, in turn, enhances employee engagement. These findings advance our understanding of how procedural justice impacts employee engagement and how procedural justice interacts with individual differences in MI centrality in influencing employee engagement.

\section{Conceptual Model and Hypotheses Development}

\section{Employee Engagement}

We follow Kahn's (1990) conceptualization of employee engagement (Christian et al. 2011; Rich et al. 2010). Employee engagement refers to "the simultaneous employment and expression of a person's 'preferred self' in task behaviors that promote connections to work and to others, personal presence (physical, cognitive, and emotional), and active, full performances," (Kahn 1990, p. 700). Engaged employees fully harness their selves in their work performance with a strong personal energy flow to their physical, cognitive, and emotional labors (Kahn 1990; Rich et al. 2010). They are not just physically present in the work place, but more importantly, they are psychologically present-more attentive, integrated, and focused in their work performance. In short, engaged employees bring their complete selves to performing their jobs (Kahn 1992; Rich et al. 2010). Employee engagement is also motivational, as it involves the allocation of personal resources to role performance (Rich et al. 2010), hence

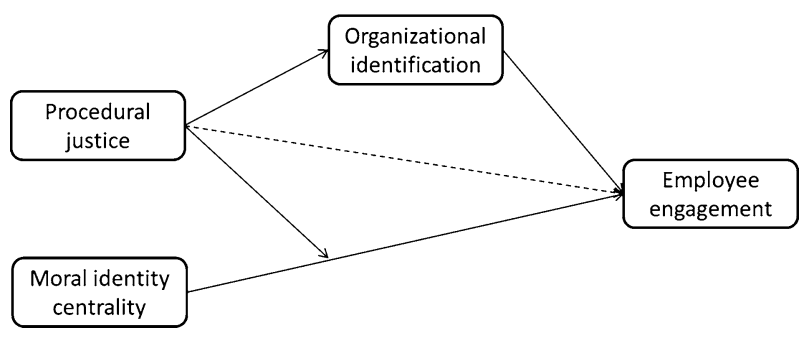

Fig. 1 Conceptual model. -...- $->$ indicates the indirect effect of procedural justice through OID opportunity costs and personal sacrifices (Bakker et al. 2005). This is not surprising, as prior research suggests that over-engagement with the work role may jeopardize a person's non-work relationships and commitment (Halbesleben et al. 2009). Clearly, the motivational and identityrelevant nature of employee engagement suggests the presence of some identity-based antecedent of employee engagement.

More engaged employees are more likely to take personal initiative at work, and therefore enhance overall unit innovativeness (Hakanen et al. 2008). At the collective level, employee engagement also boosts the bottom line of an organization (Avery et al. 2007; Harter et al. 2002). Due to these positive performance outcomes, examining what drives employee engagement is by itself a significant issue (Avery et al. 2007).

Procedural Justice and the Group Engagement Model

Procedural justice refers to employees' perception of whether they are fairly treated by the organization or team which acts as an enacting authority (Cohen-Charash and Spector 2001; Cropanzano et al. 2011; Konovsky 2000). Procedural justice typically involves the implementation of transparent and valid decision-making rules and the opportunity for employees to be involved in the decisionmaking processes (De Cremer et al. 2008). Procedural justice is considered to be a critical organizational justice factor on employee cooperative behavior (Konovsky 2000; Tyler 2000) and employee-organization relationships, such as OID (Blader and Tyler 2009; Tyler 2000), proactive behavior (Crawshaw et al. 2012), task performance (Aryee et al. 2004; Zapata-Phelan et al. 2009), and team level behaviors (Cropanzano et al. 2011).

The group value model (Lind and Tyler 1988), an earlier version of group engagement model, and its associated theory of the fairness heuristic (Lind et al. 1993) elucidates the positive effects of procedural justice. People normally would recognize the opportunity for exploitation when they are requested by an authority (i.e., the employee and supervisors) to perform a certain task. However, people have limited knowledge or ability to discern the true motives (such as being self-interested or legitimate) of these orders or requests. Thus, people tend to rely on some heuristics in making their decisions to obey or not. Procedural justice is one such decision heuristic. As noted by Lind et al. (1993, p. 226), "impressions of the process and procedures used by authorities are typically available to the perceiver prior to impressions of the outcomes they generate, judgments of the fairness of process and procedure form the heart of the fairness heuristic." The group value model suggests that procedural justice communicates two symbolic messages about group membership: individual 
members (a) being valued and respected and (b) feeling pride in the group as a whole (Lind and Tyler 1988). In general terms, when employees feel that they are fairly treated by a group, they are more willing to accept the decisions and outcomes of the procedures, comply with the group rules and laws, remain as a group member, and help the group and their peer members to perform at high levels (Restubog et al. 2008; Tyler et al. 1996).

The group engagement model extends the group value model by incorporating the central process of social/group identity formation (Blader and Tyler 2009). The basic principle of the group engagement model is that the manner in which a group makes the person think and feel about himself/herself (in other words, how the group treats the individual group member) affects the individual's behavioral effort toward the group's collective interest (Blader and Tyler 2009; Tyler and Blader 2003). People feel more respect and self-esteem from a group when they believe that the group values and appreciates them, hence they are more likely to construct their social identity with reference to their group membership (Tyler and Blader 2003), and develop a salient relational and interdependent self-construal (Holmvall and Bobocel 2008; Sedikides et al. 2008).

The group engagement model "integrates arguments that (a) procedural justice impacts behavior, (b) procedural justice impacts social identity, and (c) social identity impacts behavior, and that social identity accounts for at least part of the reason that procedural justice impacts behavior," (Blader and Tyler 2009, p. 447). From the organizational justice perspective, accordingly, the feeling of being fairly treated by an organization (i.e. procedural justice) makes employees develop stronger OID and subsequently engage in pro-organization/group behaviors (Blader and Tyler 2009; De Cremer et al. 2008; Olkkonen and Lipponen 2006; Walumbwa et al. 2009). When procedural justice is absent, some negative and harmful acts, such as retaliation, may arise (Brebels et al. 2011a, b; Skarlicki and Folger 1997).

\section{Role of OID in the Procedural Justice-Employee Engagement Relationship}

OID represents the strength of employee self-conception with reference to their organizational membership, hence acting as a salient social identity that may form part of the identity-based motivation of employee engagement. A person's social identity refers to his/her "knowledge of his membership of a social group (or groups) together with the value and emotional significance attached to that membership," (Tajfel 1981, p. 251). Social identification takes place when a social identity becomes self-defining (Turner et al. 1987). Social identity theory has been fruitfully applied to explain the employee-organization relationship (e.g., Ashforth and Mael 1989; Ashforth et al. 2008; Kim et al. 2010). An organization can act as a focal and salient social category with which employees can identify (e.g., Ashforth and Mael 1989). In addition, social identity theory is the social psychological foundation informing OID. OID occurs when organizational membership is salient to meeting an employee's self-definitional need and when an employee ties his/her self-image to the defining essence of the organization (Ashforth and Mael 1989; Fuller et al. 2006).

OID affects pro-organization behavior with the purpose of preserving the collective interests of the organization, such as enhancing organizational performance and status (Ashforth and Mael 1989). These pro-organization behaviors include job attachment, extra-role behaviors, job performance, and so on (Ashforth et al. 2008). OID is posited to affect employee engagement because OID will enable individuals to view, and internalize, an organization's success as his/her personal success (Ashforth and Mael 1989; Mael and Ashforth 1992). Employees with higher OID tend to enjoy increased engagement with their work because they view doing so is mutually beneficial (He and Brown 2013). Employee engagement may benefit not just the employee, but also the organization. We consider employee engagement as an important pro-organization work attitude that may be derived from employee OID. Employees with stronger OID tend to internalize the organization's performance associating it with their own personal job performance (Giessner 2011; Mael and Ashforth 1992). Hence, employees are more likely to fully engage with their job for the purpose of enhancing the mutually-related personal and organization performances. Indeed, Ashforth et al. (2008) argue that the identities that individuals define for themselves, with reference to their work roles (e.g., organizational identity), can drive the allocation of self-energy (cognitive, emotional, and physical) to the work roles. Based on the above argument, we propose:

H1 OID mediates the effect of procedural justice on employee engagement.

\section{Centrality and Employee Engagement}

MI was first proposed by Blasi (1984) and further expanded and developed by other scholars (e.g., Aquino and Reed 2002), who defined MI as a self-schema-beliefs and ideas people have about themselves-organized around a set of moral trait associations, such as being caring, hard-working, considerate, and helpful. As MI represents knowledge about one's self with regard to some moral traits (Aquino and Reed 2002; Aquino et al. 2011), MI can be a source of personal intrinsic motivation. More specifically, people with stronger MI centrality-the degree to which the moral 
traits are central to the self-concept-are more likely to activate the relevant MI-based knowledge to inform, guide, and regulate their behaviors (Aquino et al. 2009).

MI-based motivation of employee engagement can be informed by the basic notion of identity-based motivation (e.g., Alvesson and Willmott 2002; Das et al. 2008; Shavitt et al. 2009), which posits that a salient identity (e.g., central to a personal overall self-concept) "triggers action tendencies and mindsets that facilitate meeting identity goals," (Shavitt et al. 2009, p. 263). The mindset associated with an identity filters information processing and encourages attitudes that are consistent with the expectation arising from the focal identity (Das et al. 2008), as people have the inherent desire to preserve and stabilize their self-view by "thinking and behaving in ways that perpetuate their conceptions of self" (Swann et al. 1987, p. 881). MI centrality has been found to regulate behaviors in a wide range of contexts. For example, MI centrality enhances social volunteering (Aquino and Reed 2002); charitable donation and provision of public goods (Aquino et al. 2009); Consumer's use intention of pirated software (Chen et al. 2009) and general ethical behavior (Reynolds and Ceranic 2007). Meanwhile people with stronger MI centrality are less likely to cheat (Reynolds and Ceranic 2007) or lie (Aquino et al. 2009).

Accordingly, employees with a strong MI tend to define their self-concepts with some typical virtuous characteristics (Aquino and Reed 2002), and tend to behave in accordance with these virtues, such as being generous, helpful, hardworking, caring, and honest. MI is also an important employee identity that impacts employee behavior (e.g., McFerran et al. 2010; Shao et al. 2008; Skarlicki et al. 2008; Treviño et al. 2006; Weaver 2006). The typical traits associated with MI are particularly relevant personal resources for job-related attitudes. These personal resources, derived from $\mathrm{MI}$, enable employees to feel more responsible for the success of their organization (including both their own performance and that of colleagues). For example, McFerran et al. (2010) found that MI centrality has a positive effect on employee helping behaviors. Brebels et al. (2011a, b) found that managers with stronger MI centrality are more likely to enact fair procedures and grant voice to subordinates.

The impact of MI centrality on employee engagement can be inferred by two of the psychological foundations of job engagement proposed by Kahn (1990): psychological meaningfulness and psychological availability. Psychological meaningfulness refers to one's feeling that a worthwhile, useful, and valuable return on investments of "one's self in a currency of psychical, cognitive, or emotional energy," has been made (Kahn 1990, pp. 703-704). It is related to one's ability to give to others and to the work itself as a sense of self-fulfillment.
As noted earlier, as employees would normally recognize the positive implications of their own employee engagement for the organization and for others in the organization, an employee with stronger MI centrality tends to more fully engage with his/her job. Persons probably should not be considered truly moral, if under normal circumstances they cannot even fulfill their own duties, as moral traits include virtues such as being hard-working (Aquino and Reed 2002).

Psychological availability refers to the sense of having the physical, emotional, or psychological resources to personally engage with one's job (Kahn 1990). It captures one's readiness to engage, despite the distractions an individual may experience as a member of wider social systems. Engaged employees are more available and ready to fully devote their selves to their work role performances whilst coping with the various demands of the non-work aspects of their lives (Kahn 1990). Thus, employee engagement requires a certain level of self-sacrifice (Kahn 1990; Rich et al. 2010). Because employees with stronger MI centrality are more likely to be self-sacrificing and altruistic, they are more likely to feel available and ready to sacrifice personal resources to engage with their jobs. Thus, we propose the following hypothesis.

H2 MI Centrality has a positive effect on employee engagement.

\section{Procedural Justice and MI Centrality}

Although procedural justice may enhance one particular element of identity-based motivation of employee engagement (i.e., relational concern derived from OID), the impact of procedural justice, in addition to its indirect effect via OID, is driven by the employee's construed situation. In general, we expect that MI centrality has a weaker effect on employee engagement when perceived procedural justice is higher, drawing on the strong situation hypothesis (e.g., Cooper and Withey 2009; Meyer et al. 2010; Mischel 1977).

The literature on person-situational determinants of behavior agrees that both personal factors, such as stable personal identity and personality, and situational variables affect behavior (Sherman et al. 2010). More importantly, the interaction between personal factors and situational variables explains additional variance in behavior (Cooper and Withey 2009; Mischel 1977; Tett and Burnett 2003; Treviño 1986). It is important to note that the situation is construed by the beholders. As noted by Mischel, "any given, objective stimulus condition may have a variety of effects, depending on how the individual construes and transforms it" (1977, p. 253). Similarly, Bem and Allen (1974) argued that "the classification of situations... will 
have to be in terms of the individual's phenomenology, not the investigator's," (1974, p. 518).

How a situation weakens or strengthens the effects of personal traits or cognitions depends on the strength of the situation (Mischel 1977). A strong situation is is unambiguous (Mischel 1977; Shane et al. 1996). As noted by Mischel (1977, p. 276), "when the situation is ambiguously structured... so that subjects are uncertain about how to categorize it and have no clear expectations about the behaviors most likely to be appropriate." A strong situation provides clear guidelines for employee behavior and minimizes individual interpretation or inference. Therefore, the impacts of individual differences tend to be weaker under strong work situations. When a work situation is characterized by more uncertainty or ambiguity, there is a greater scope for individual information-seeking and sense-making, which results in a stronger impact on individual differences on behaviors (Mischel 1977; Shane et al. 1996).

Recent organizational and management research has provided strong empirical evidence on the strong situation's moderating effect on the direct effects of individual differences on employee behaviors. For example, Klein et al. (2011) found that value diversity has a weaker positive effect on team conflict when the team leader shows stronger task-focused team leadership. Through a metaanalysis, Meyer et al. (2009) found that conscientiousness has a weaker positive effect on employee organizational citizenship behavior when occupation-level situational strength is stronger. Meyer et al. (2011) developed a construct that measures job-related situational strength directly and found that employee personality traits have a weaker (stronger) effect on employee organizational citizenship behavior and performance when the situational strength is stronger (weaker). Conceptually, Mullins and Cummings (1999), drawing upon situational strength framework, argue that individual differences in the personality traits of strategic decision makers are less likely to exert influence on the firm's decision to undertake a strategic change in strong situations rather than in weaker situations. Drawing upon the same framework, Bowen and Ostroff (2004) propose that individual differences are more likely to exert a stronger (weaker) effect on employee performance when the human resource management system is weaker (stronger). Specifically regarding MI-based motivation, prior research has provided some preliminary evidence on the situation's moderating effect on MI self-regulation. For example, Aquino et al. (2009) observe an attenuated regulatory effect of MI centrality when external regulation or incentives are present.

In this research, employee MI centrality can be considered as a personal factor (i.e., individual difference), whereas the situational factor pertains to employee perceived procedural justice. In the case of the interaction between MI centrality and procedural justice in influencing employee engagement, we have argued that: (a) MI centrality enhances employee engagement due to its self-regulatory power, and (b) that procedural justice enhances employee engagement because it enhances employee OID. In other words, employee engagement can be driven by both individual differences and volition, such as the motivation of verifying and enacting a person's moral identity; as well as by a social economic exchange relationship context as characterized by high procedural justice (Blau 1964; Konovsky 2000). High procedural justice represents a strong situation because fair procedures enhance people's trust and confidence in the other party (the acting authority) within a social exchange relationship (or psychological contract) so that their self-interests can be assured or reciprocated (Blau 1964; Konovsky 2000; Konovsky and Pugh 1994). Indeed, it has been suggested that high procedural justice (i.e., high procedural consistency) is associated with higher situational strength (Meyer et al. 2010). Thus for employees who perceive stronger procedural justice operating in their work organization, their work situation is considered to be a strongly regulated social exchange relationship. Under such a strong justicebased social exchange work situation, individual moral self-regulation on employee engagement would be less relevant. Conversely, in a poorly regulated context (i.e., low or procedurally unfair), the individual difference of moral identity centrality would find expression through differences in employee engagement and fulfillment of the contractual relationship. Thus, when procedural justice is high, MI centrality plays a less important role in motivating employee engagement; whilst procedural justice is low, the regulation of MI centrality would prevail in employee engagement. Therefore, we propose:

H3 Procedural justice compensates the effect of MI centrality on employee engagement, so that when procedural justice is higher (lower), individual differences in MI centrality play a weaker (stronger) role in employee engagement.

\section{Method}

\section{Sample}

A leading financial service organization in the United Kingdom agreed to distribute our survey among its employees in its headquarters. An online survey was created and posted on the organization's intranet with 222 usable responses being recorded with a response rate of over $22 \%$. To enhance response credibility, the respondents were assured of anonymity/confidentiality as well as the academic nature of the survey. They were informed that 
the data were to be accessible and used independently by academic researchers not affiliated with the organization. Participants were back-office white collar workers from the IT, HR, Marketing, and Communications departments in the head office. The mean age of the respondents was 37.93 years, the mean tenure of employment was 7.70 years, and $55.9 \%$ of respondents were female. The education distribution was as follows: school leaver $(15.3 \%)$, higher education diploma (36.5\%), first degree $(39.2 \%)$, masters degree $(8.1 \%)$, and doctoral degree (.9\%). The demographic profile of the respondents was confirmed by a human resources manager of the organization as highly typical of the Head Office employees overall.

\section{Measures}

All variables were measured by seven-point Likert-type scales ( 1 means 'strongly disagree' and 7 means 'strongly agree'). Employee engagement was measured by the scale developed by Rich et al. (2010). This scale was chosen because it measures three components of employee engagement (i.e., physical engagement, emotional engagement, and cognitive engagement), which has been considered to be more closely based on the Kahn's $(1990,1992)$ conceptualization of employee engagement (Rich et al. 2010). The scale was considered as a unidimensional and second-order construct, hence an aggregate score of overall employee engagement is used as the latent variable (Rich et al. 2010). For each component, we selected three to four items from the original lists to avoid over-repetition in the items due to very similar meanings of some of the items. For example, originally the sub-scale of physical engagement had six items, with the last two items being extremely similar to the earlier two items (i.e., 'I strive as hard as I can to complete my job' vs. 'I try my hardest to perform well on my job,' and 'I exert a lot of energy on my job' vs. 'I devote a lot of energy to my job'). Hence we removed the last two items from the scale. This selection process was aided by the consultation of several management consultants and academics working in the field and managers/employees of the focal organization. The appendix lists the scales and items [with their respective Cronbach's alphas and factor loadings (FL)] for employee engagement and other variables used in this study. Cronbach's alphas were: .94 (overall; with .94 for physical engagement, .94 for emotional engagement, and .91 for cognitive engagement).

Moral identity centrality (five items) was measured by the widely used scale developed by Aquino and Reed (2002). The scale starts with instructing the participants to imagine how a person, with the characteristics of being caring, compassionate, fair, friendly, generous, helpful, hardworking, honest, and kind, would think, feel, and act.
Then the participants were asked to answer a set of Likert scale questions such as: "It would make me feel good to be a person who has these characteristics", and "Being someone who has these characteristics is an important part of who I am." The Cronbach's alpha of this scale was .83.

OID was measured by five items from the widely used scale developed by Mael and Ashforth (1992). A sample item is 'When someone criticizes $\mathrm{X}$, it feels like a personal insult.' The Cronbach's alpha was .90 .

Procedural justice was measured by 4 items previously used by Rupp and Cropanzano (2002). Sample items are: 'The organization's procedures and guidelines are very fair,' and 'I can count on the organization to have fair policies.' The Cronbach's alpha was .85 .

Analyses and Results

\section{Scale Validity}

To examine the validity of the scales utilized in this study, we used M-PLUS 6.0 (Muthen and Muthen 2010) to conduct confirmatory factor analysis (CFA), following the approach of Mayer et al. (2012). More specifically, we compared the fit of a model in which measures of all four factors (i.e., moral identity, procedural justice, OID, and employee engagement) were set to load on their respective factors, and more constrained models in which some factors (e.g., OID and moral identity) were set to load on a single factor. Based on the suggestion of prior research (Rich et al. 2010), employee engagement was treated as a second-order factor which consists of three first-order factors (physical, cognitive, and emotional). CFA results demonstrated that the hypothesized 4-factor model fits the data significantly better than all other alternative models, providing evidence for the validity and independence of all the measurements utilized and suggests that common method variance is not a serious problem in this study. The detailed CFA results can be seen in Table 1. The Appendix lists the measurement items and their corresponding FLs from the proposed four-factor model. Table 2 reports the descriptive statistics of all variables used in the study. These results clearly demonstrate the validities of our measures and variables (Fornell and Larcker 1981). FLs are all above the threshold of .50. AVE scores of all variables are higher than .50. The square roots of the AVE scores of all variables are higher than all correlations of the focal variables with other variables.

\section{Analysis Strategy}

We used structural equation modeling (SEM) to conduct hypotheses testing with M-PLUS 6.0 (Muthen and Muthen 2010) because SEM mediation models can perform better 
Table 1 Confirmatory factor analysis

\begin{tabular}{|c|c|c|c|c|c|c|}
\hline Model & $\chi^{2}$ & $\mathrm{~d} f$ & CFI & TLI & RMSEA & SRMR \\
\hline Four-factor model & 644.24 & 266 & .93 & .92 & .08 & .07 \\
\hline Three-factor model: moral identity and OID combined & 1034.48 & 269 & .85 & .83 & .11 & .09 \\
\hline Three-factor model: procedural justice and employee engagement combined & 886.51 & 269 & .87 & .86 & .10 & .08 \\
\hline One-factor model & 1944.59 & 275 & .67 & .64 & .17 & .10 \\
\hline
\end{tabular}

CFI the comparative fit index, TLI the Tucker Lewis index, RMSEA the root-mean-square error of approximation, SRMR the standardized root mean square residual

Table 2 Descriptive statistics, reliability coefficients and correlations of study variables

\begin{tabular}{lllllll}
\hline Variable & Mean & SD & 1 & 2 & 3 & 4 \\
\hline 1. Procedural justice & 5.15 & 1.22 & .77 & & & \\
2. MI centrality & 5.89 & 1.10 & $.46^{* *}$ & .74 & & \\
3. OID & 4.68 & 1.41 & $.56^{* *}$ & $.49^{* *}$ & .81 & \\
4. Employee & 5.75 & 1.21 & $.53^{* *}$ & $.60^{* *}$ & $.65^{* *}$ & .93 \\
$\quad$ engagement & & & & & & \\
AVE & & & .60 & .55 & .66 & .87 \\
\hline
\end{tabular}

Diagonal values represent the square roots of AVE scores

$A V E$ Average variance extracted

** Significance at the $1 \%$ level

than traditional regression analyses (Iacobucci et al. 2007). To test the mediation hypotheses, the bootstrapping method was used (MacKinnon et al. 2004). Bootstrapping does not require the basic assumption of multivariate normality, which is required by the causal steps approach of Baron and Kenny (1986). Furthermore, bootstrapping provides a powerful and robust method of obtaining confidence intervals for specific indirect effects and their significance levels. To test the moderating effect, we created an interaction term with two latent variables and regressed the interaction term on the outcome variable.

\section{Results and Hypotheses Testing}

The detailed results of the SEM are shown in Table 3 and Fig. 2 is a graphical illustration of results.

To test the main and mediation effects, we ran Model 1, which does not include the interaction term. The SEM results showed that the proposed model fit the data well $\left(\chi^{2}=666.73, \quad \mathrm{df}=267, \quad \mathrm{RMSEA}=.07, \quad \mathrm{CFI}=.92\right.$, TLI $=.91)$. Absolute fit indices such as CFI, TLI should be above .90 , with an RMSEA between .08 to .10 providing a mediocre fit, with a result below .08 showing a good fit (e.g., Hooper et al. 2008; Hu and Bentler 1999; MacCallum et al. 1996). Apparently, all of the fit indices of
Table 3 Structural equation path coefficients

\begin{tabular}{lll}
\hline & Model 1 & Model 2 \\
\hline Procedural justice-employee engagement & .08 & .07 \\
Procedural justice-OID & $.67^{* *}$ & $.67^{* *}$ \\
OID-employee engagement & $.37^{* *}$ & $.43^{* *}$ \\
MI centrality_employee engagement & $.47^{* *}$ & $.31^{* *}$ \\
MI centrality x procedural justice- & & $-.32^{* *}$ \\
$\quad$ Employee engagement & & $.53^{* *}$ \\
$R^{2}$ & & $.55^{* *}$ \\
$\Delta R^{2}$ & & $.02^{* *}$ \\
\hline
\end{tabular}

Standardized numbers shown

OID organizational identification, $M I$ moral identity

** Indicate significance at the $1 \%$ level

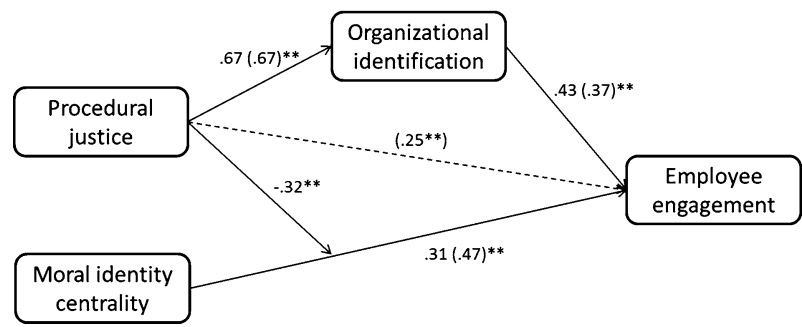

Fig. 2 Conceptual model with estimated coefficients. $* * p<.01$. Standardized values shown; Numbers in bracket are from Model 1. -..-- indicates the indirect effect of procedural justice through OID

our models meet these criteria. As can be seen in Table 3 (Model 1), the direct effect of procedural justice on employee engagement was non-significant $(\beta=.08$, $p>.10)$. Furthermore, the effect of procedural justice on OID was significant $(\beta=.67, p<.01)$ and the effect of OID on job engagement was significant $(\beta=.37, p<.01)$. We calculated that the indirect effect of procedural justice on employee engagement through OID was significant $(\beta=.25, p<.01,95 \%$ CIS from .16 to .34). All these above results showed that OID fully mediated the effect of 
procedural justice on employee engagement, thus Hypothesis 1 was supported.

Hypothesis 2 proposed that MI centrality has a positive effect on employee engagement. As can be seen in Table 3 (Model 1), the coefficient from MI centrality to job engagement $(\beta=.47, p<.01$ ) was significant. Therefore, H2 was supported.

Hypothesis 3 suggested that procedural justice compensates for the effect of MI centrality on employee engagement, so that when procedural justice is higher (lower), individual differences in MI centrality play a weaker (stronger) role in employee engagement. To test Hypothesis 3, we added an interaction between MI centrality and procedural justice to the model to predict employee engagement. The interaction model (Model 2 in Table 3$)$ has an adequate fit $\left(\chi^{2}=794.55, d f=291\right.$, $\mathrm{RMSEA}=.08, \mathrm{CFI}=.91, \mathrm{TLI}=.90)$ and the interaction of MI centrality and procedural justice does have a significant negative effect on employee engagement $(\beta=$ $-.32, p<.01)$. Adding this interaction term improves the $R^{2}$ of job engagement slightly from 53 to .55 , with an increase of $.02(p<.01)$.

We calculated the effect sizes and their significance levels of the effect of MI centrality on employee engagement at high and low levels (one standard deviation above or below the mean of procedural justice). When procedural justice is high, the effect of MI centrality on employee engagement is non-significant $(\beta=-.01$, ns), whilst when procedural justice is low, the effect of MI centrality on employee engagement is positive and significant $(\beta=.63$, $p<.001)$. Therefore, H3 was partially supported.

In addition, we also compared the hypothesized model with other alternative nested models. The results are shown in the Table 4. As indicated in Table 4, the fit indices of these nested models are not found to be significantly better than those of the proposed hypothesized model. In addition, these nested models are not theoretically-based; therefore we conclude that the hypothesized model is a superior one.

Table 4 Comparing with other alternative nested models

\begin{tabular}{llllll}
\hline Model & $\chi^{2}$ & $\mathrm{~d} f$ & CFI & TLI & RMSEA \\
\hline $\begin{array}{l}\text { The hypothesized main effect } \\
\text { model (model 1 of Table 1) }\end{array}$ & 666.73 & 267 & .92 & .91 & .07 \\
$\begin{array}{c}\text { The hypothesized model } \\
\text { (model 2 of Table 1) }\end{array}$ & 794.55 & 291 & .91 & .90 & .08 \\
$\begin{array}{l}\text { Alternative Model 1: Adding } \\
\text { MI-OID }\end{array}$ & 793.44 & 290 & .91 & .90 & .09 \\
$\begin{array}{l}\text { Alternative Model 2: Adding } \\
\text { MI-OID and MI-PJ }\end{array}$ & 792.41 & 289 & .91 & .90 & .09 \\
\hline
\end{tabular}

$\overline{M I \text { moral identity, } O I D \text { organizational identification, } P J \text { procedural }}$ justice

\section{Discussion and Conclusion}

\section{Theoretical Implications}

In summary, consistent with our expectations, we found that procedural justice impacts employee engagement via OID and compensates for the effect of MI centrality on employee engagement. The results of this research make a number of significant theoretical contributions to the literature of procedure justice, job engagement, identity-based motivation, and MI. Earlier research on the antecedents of employee engagement have mainly focused on job characteristics, leadership, and dispositional traits (see Christian et al. 2011 for a review). More recently, Rich et al. (2010) find that both job resources (e.g., value congruence and perceived organizational support) and personal resources (e.g., core selfevaluation) have additive independent significant effects on job engagement. Other recent research suggests that both job resources and personal resources are interrelated factors, as well as reciprocal outcomes, of employee engagement (e.g., Hakanen et al. 2008; Xanthopoulou et al. 2009). Apparently, few existing studies have approached employee engagement from an identity-based motivation perspective, justice perspective, or a combination of them, which is the theoretical gap we filled with this study, despite the fact that employee social identities and justice perception are interrelated motivations for employee engagement.

This research supports the notion that procedural justice positively impacts employee engagement, hence it extends the list of potential positive outcomes of procedural justice to include a focal employee work role performance. Procedural justice is motivational, and hence has been widely examined as a potential motivational force for employee behaviors and performance. Prior research has mainly focused on employee 'extra-role' or citizenship behaviors (Blader and Tyler 2009) and task performance (e.g., Aryee et al. 2004; Zapata-Phelan et al. 2009). Recent research has noticed the impact of procedural justice on proactive behavior-exhibition of innovativeness, future orientation and self-motivation when organizations are facing difficulties in these areas (Crawshaw et al. 2012). Given the increasingly observed beneficial effects of employee engagement for both employees and organizations (Christian et al. 2011; Harter et al. 2002; Rich et al. 2010), it is important to assess whether and how procedural justice motivates employee engagement which is also considered as requiring employee motivation (Parker et al. 2010). In a similar vein, this research extends the application of the group engagement model by including job engagement as a criterion variable. The group engagement model offers a useful theoretical explanation for how procedural justice affects employee behaviors, such as citizenship behavior, via OID (Blader and Tyler 2009). 
As for the contribution this study makes to the employee engagement and identity-based motivation literatures, this research originally proposed, and the results support, an identity-based motivation for employee engagement. Identity-based motivation has received increased attention in employee behavior research (Ashforth et al. 2008; He and Brown 2013). However this body of literature is still limited in that rarely are multiple employee identities assessed with regard to their respective (be them competing or complementary) impacts on employee motivations, attitudes, and performance (Brown and Treviño 2006). Employee identities are particularly relevant for employee engagement motivation, as employee engagement involves volitional allocation of personal energy/resources into work roles and a certain level of self-sacrifice (Halbesleben et al. 2009; Rich et al. 2010). However, prior research has not yet formally theorized or tested the identity-based motivation of employee engagement. This research incorporates two important employee identities, namely OID and MI, to explain employee engagement. We draw upon the group engagement model (e.g., Blader and Tyler 2009; Tyler and Blader 2003) and person-situation framework (e.g., Cooper and Withey 2009; Meyer et al. 2010; Mischel 1977) to propose a theoretical framework, which integrates procedural justice and employee identity-based motivation to explain employee engagement. Specifically, we propose and support that OID is more subjective to the influence of organizational dynamics (e.g., fair procedures), hence is able to internalize external regulation of procedural justice to personal relational motivations. Although MI centrality itself is more stable, its motivational power could be compensated for by procedural justice. Thus, incorporating MI into the effects of the justice perspective offers a more comprehensive view of an integrated justice/identity-based motivational model of employee engagement.

Third, regarding the MI literature itself, so far research has mainly focused on its impact on people's voluntary and ethical behaviors (e.g., Aquino et al. 2009; Aquino et al. 2011; Reynolds and Ceranic 2007; Winterich et al. 2009). In addition, research on the impact of MI on employee behavior is still very rare, except for work focusing on organizational citizenship behavior (McFerran et al. 2010) and sabotage behavior (Skarlicki et al. 2008). Together with a few recent studies (e.g., McFerran et al. 2010; Skarlicki et al. 2008), this research suggests an important avenue of research for explaining employee in-role work attitudes and behaviors by taking a moral identity perspective into account. This research not only demonstrates how MI centrality impacts employee job engagement, but also supports that procedural justice may represent a strong work situation that attenuates the effect of individual differences (i.e., MI centrality) on employee engagement. On the other hand, this effect can be seen as beneficial, as it suggests that procedural justice compensates for the effect of MI centrality by showing that when either procedural justice or MI centrality is high, employee engagement tends to be higher regardless. Thus, overall, procedural justice is effective in promoting employee engagement.

Other macroeconomic and environmental factors might also impact employee engagement in organizations. For example, companies with highly engaged employees are more likely to deal with the challenges of recession and make and implement tough decisions (MacLeod and Clarke 2009). In addition, other important work environmental variables, such as length of work shift, staff level, and skill level, can also influence employee engagement (Simpson 2009). It is recommended that future studies further examine the roles of these variables that can influence, enhance, or inhibit the dynamic and complex relationships between employee engagement and important work behaviors and outcomes.

\section{Managerial Implications}

There are several practical implications of the current research. First, our research findings suggest that managers should be aware of the positive impact of procedural justice on employee engagement. This is particularly relevant for many sectors (e.g., service companies) where job burnout, and thus turnover intention, is more likely to happen. More specifically, it is important for managers to implement transparent and valid decision-making processes and rules and to offer the opportunity for employees to voice their opinions, as participation in collective decision-making processes can increase employees' perception of procedural justice. This type of procedural justice can consequently increase employees' OID, and subsequently employee engagement.

One important implication stems from the interesting finding that procedural justice compensates for the effect of MI centrality on employee engagement, so that when procedural justice is higher (lower), individual differences in MI centrality play a weaker (stronger) role in employee engagement. This finding suggests that managers should consider individual differences, especially identities, when they are trying to promote procedural justice in their organizations. Our results suggest that organizations may benefit more by enhancing procedural justice perceptions particularly among employees who value less intrinsic moral motivation in employee engagement. Supervisors should be encouraged to gauge the MI centrality of their subordinates in order to feed important employee individual difference information to management.

In general, MI centrality is less susceptible than OID to the influence of organizational interventions. Recent research suggests that ethical leadership may promote employee MI 
centrality by setting high moral standards (Zhu et al. 2011), which could consequently develop employee engagement directly, but it also interacted with procedural justice (i.e., making employees less volatile in responding to low procedural justice perceptions) in affecting employee engagement. We would consider this suggestion as tentative and requiring further evidence. Nevertheless, it would be beneficial for organizations to assess and monitor MI centrality when making recruitment, hiring, and promotion decisions.

\section{Limitations and Future Research}

This research has a number of limitations, which suggest important future research directions. First, the research is based on a cross-sectional survey, with all measures being self-reported. On the one hand, self-reports have been argued to be appropriate for variables that are perceptual or related to private events (Chan 2009; Conway and Lance 2010). Thus the endogenous variables in our model (OID and employee engagement) are suitably measured by selfreport. It has also been argued that self-reporting is not necessarily inferior to other types of subjective rating, such as supervisor or peer ratings (Conway and Lance 2010). On the other hand, a longitudinal research design would be more desirable, and multi-source data are still encouraged in future studies. In addition, prior research has also demonstrated that common method bias is a less severe a concern when the model involves interaction effects (Evans 1985; Siemsen et al. 2010).

An additional limitation is that we did not include other types of justice, such as interactional justice and distributive justice that could also be important factors that can influence OID and employee engagement. In addition, it is also possible that followers' value congruence with the organization (Fenton and Inglis 2007) could be an important moderating variable that might strengthen the effect of procedural justice on OID. Similarly, the nature and direction of the interactive effect between procedural justice and MI centrality could depend on the criterion variables. This study examines employee engagement as the outcome variable. As employee engagement is motivational (Christian et al. 2011; Rich et al. 2010), we applied motivational theory to develop the compensatory effect between procedural justice and MI centrality in promoting job engagement. Would the same pattern emerge for other outcome variables, such as extra-role behaviors and job performance? An alternative perspective, namely fairness theory (Folger and Cropanzano 2001), exists regarding individual differences in the effect of organizational justice on employee job performance (see, e.g., Colquitt et al. 2006). All of these research questions are worthy of further exploration in future studies.
Employees may identify with a particular person (e.g., supervisors) and the organization as whole. The former can be named relational identification (e.g., Sluss and Ashforth 2007, 2008). We did not incorporate relational identification in our research because procedural justice in our research refers to how organizational employees perceived how fairly they are treated by the organization, instead of by supervisors (Konovsky 2000). Future research can examine procedural justice as enacted by the supervisor. In this case, supervisor-related procedural justice may be different from organizational-level procedural justice. As a result, future research can examine how organizationallevel procedural justice and supervisor-related procedural justice may have different impacts on employee relational identification and OID, which in turn affect employee job engagement.

This study used a sample in the financial services sector in the UK. It should be beneficial for future research to test this study's theoretical model in other western countries, such as the USA. On the other hand, procedural justice may play a different role in Eastern cultures, where authoritarianism and power distance are relatively higher. It is possible that, in such cultures, procedural justice might play a less important role in influencing OID and/or employee engagement because employees in these cultures may think that it is within leaders' discretion and power to be relatively more directive in making some decisions. We strongly encourage future research to test our model in Eastern cultures which will help better understand the crosscultural generalizability of this proposed theoretical model.

Another limitation is that we did not measure objective indicators of job performance, which could be adopted to further determine whether procedural justice and OID influences objective measures of follower performance. Therefore, we suggest that future research use some objective and hard measures of performance, to investigate the relationships proposed in this study in a more in-depth manner and to create a more insightful understanding of the complex dynamics inherent in the theoretical model of this study. Furthermore, this research is limited by the fact that the sample is drawn from one organization. Although such an initial empirical examination provides important evidence on our proposed conceptual model, we encourage future research to test our model with data from other contexts.

In conclusion, this study provides researchers investigating procedural justice, moral identity, OID, and employee engagement with a preliminary map of how these constructs are related. The justice perspective and identity perspective can provide complementary and compensatory effects over employee engagement. We hope this preliminary study provides further impetus for examining the role of identity 
and justice in influencing employee engagement and task performance.

\section{Appendix: Measurement Items and Loadings}

Employee Engagement (alpha $=.94)$

Physical Engagement $(F L=.90)($ alpha $=.94)$

1. I work with intensity on my job $(\mathrm{FL}=87)$

2. I exert my full effort to my job $(\mathrm{FL}=.92)$

3. I devote a lot of energy to my job $(\mathrm{FL}=.93)$

4. I try my hardest to perform well on my job $(\mathrm{FL}=.84)$

Emotional Engagement $(F L=.92)($ alpha $=.94)$

1. I am enthusiastic in my job $(\mathrm{FL}=.94)$

2. I feel energetic at my job $(\mathrm{FL}=.93)$

3. I am proud of my job $(\mathrm{FL}=.87)$

4. I am excited about my job $(\mathrm{FL}=.83)$

\section{Cognitive Engagement $(F L=.97)($ alpha $=.91)$}

1. At work, my mind is focused on my job $(\mathrm{FL}=.93)$

2. At work, I focus a great deal of attention on my job $(\mathrm{FL}=.90)$

3. At work, I am absorbed by my job $(\mathrm{FL}=.82)$

OID (alpha $=.90)$

1. When someone criticizes $\mathrm{X}$, it feels like a personal insult $(\mathrm{FL}=.86)$

2. I am very interested in what others think about $X$ $(\mathrm{FL}=.72)$

3. $\mathrm{X}$ 's successes are my successes $(\mathrm{FL}=.85)$

4. When someone praises $\mathrm{X}$, it feels like a personal compliment $(\mathrm{FL}=.91)$

5. If a story in the media criticized $X$, I would feel embarrassed $(\mathrm{FL}=.70)$

Procedural Justice $($ alpha $=.85)$

1. $\mathrm{X}^{\prime}$ procedures and guidelines are very fair $(\mathrm{FL}=.91)$

2. The procedures the organization uses to make decisions are not fair $(\mathrm{FL}=.60)^{\mathrm{R}}$

3. I can count on the organization to have fair policies $(\mathrm{FL}=.91)$

4. We don't have any fair policies at the organization $(\mathrm{FL}=.62)^{\mathrm{R}}$
Moral Identity Centrality (alpha $=.83)$

Listed below are some characteristics that might describe a person:

Caring, Compassionate, Fair, Friendly, Generous, Helpful, Hardworking, Honest, Kind

The person with these characteristics could be you or it could be someone else. For a moment, visualize in your mind the kind of person who has these characteristics. Imagine how that person would think, feel, and act. When you have a clear image of what this person would be like, answer the following questions

1. It would make me feel good to be a person who has these characteristics $(\mathrm{FL}=.94)$

2. Being someone who has these characteristics is an important part of who I am $(\mathrm{FL}=.91)$

3. I would be ASHAMED to be a person who had these characteristics $(\mathrm{FL}=.56)^{\mathrm{R}}$

4. Having these characteristics is NOT really important to me $(\mathrm{FL}=.58)^{\mathrm{R}}$

5. I strongly desire to have these characteristics $(\mathrm{FL}=.61)$

Note: ${ }^{\mathrm{R}}=$ Reverse coding

\section{References}

Alvesson, M., \& Willmott, H. (2002). Identity regulation as organizational control: Producing the appropriate individual. Journal of Management Studies, 39(5), 619-644.

Aquino, K., Freeman, D., Reed, A, I. I., Lim, V., \& Felps, W. (2009). Testing a social-cognitive model of moral behavior: The interactive influence of situations and oral identity centrality. Journal of Personality and Social Psychology, 97, 123-141.

Aquino, K., McFerran, B., \& Laven, M. (2011). Moral identity and the experience of moral elevation in response to acts of uncommon goodness. Journal of Personality and Social Psychology, 100, 703-718.

Aquino, K., \& Reed, A, I. I. (2002). The self-importance of moral identity. Journal of Personality and Social Psychology, 83(6), $1423-1440$.

Aryee, S., Chen, Z. X., \& Budhwar, P. S. (2004). Exchange fairness and employee performance: An examination of the relationship between organizational politics and procedural justice. Organizational Behavior and Human Decision Processes, 94(1), 1-14.

Ashforth, B. E., Harrison, S. H., \& Corley, K. G. (2008). Identification in organizations: An examination of four fundamental questions. Journal of Management, 34(3), 325-374.

Ashforth, B. E., \& Mael, F. (1989). Social identity theory and the organisation. Academy of Management Review, 14, 20-39.

Avery, D. R., McKay, P. F., \& Wilson, D. C. (2007). Engaging the aging workforce: The relationship between perceived age similarity, satisfaction with coworkers, and employee engagement. Journal of Applied Psychology, 92(6), 1542-1556. 
Bakker, A. B., Demerouti, E., \& Schaufeli, W. B. (2005). The crossover of burnout and work engagement among working couples. Human Relations, 58(5), 661-689.

Baron, R. M., \& Kenny, D. A. (1986). The moderator-mediator variable distinction in social psychological research: Conceptual, strategic, and statistical considerations. Journal of Personality and Social Psychology, 51(6), 1173-1182.

Bem, D. J., \& Allen, A. (1974). On predicting some of the people some of the time: The search for cross-situational consistencies in behavior. Psychological Review, 81(6), 506-520.

Bernerth, J., \& Walker, H. J. (2012). Reexamining the workplace justice to outcome relationship: Does frame of reference matter? Journal of Management Studies, 49(5), 945-969.

Blader, S. L., \& Tyler, T. R. (2009). Testing and extending the group engagement model: Linkages between social identity, procedural justice, economic outcomes, and extrarole behavior. Journal of Applied Psychology, 94(2), 445-464.

Blasi, A. (1984). Moral identity: Its role in moral functioning. In W. Kurtines \& J. Gewirtz (Eds.), Morality, moral behaviour and moral development (pp. 128-139). New York, NY: Wiley.

Blau, P. (1964). Justice in social exchange. Sociological Inquiry, 34(2), 193.

Bowen, D. E., \& Ostroff, C. (2004). Understanding HRM-firm performance linkages: The role of the "strength" of the HRM system. Academy of Management Review, 29(2), 203-221.

Brebels, L., De Cremer, D., \& Van Dijke, M. (2011a). Using selfdefinition to predict the influence of procedural justice on organizational-, interpersonal-, and job/task-oriented citizenship behavior. Journal of Management. doi:10.1177/014920631141 0605.

Brebels, L., De Cremer, D., Van Dijke, M., \& Van Hiel, A. (2011b). Fairness as social responsibility: A moral self-regulation account of procedural justice enactment. British Journal of Management, 22, S47-S58.

Brown, M. E., \& Treviño, L. K. (2006). Ethical leadership: A review and future directions. Leadership Quarterly, 17(6), 595-616.

Chan, D. (2009). So why ask me? Are self-report data really that bad? In C. E. Lance \& R. J. Vandenberg (Eds.), Statistical and methodological myths and urban legends: Doctrine, verity and fable in the organizational and social sciences (pp. 311-338). New York: Routledge.

Chen, M., Pan, C., \& Pan, M. (2009). The joint moderating impact of moral intensity and moral judgment on consumer's use intention of pirated software. Journal of Business Ethics, 90, 361-373.

Christian, M. S., Garza, A. S., \& Slaughter, J. E. (2011). Work engagement: A quantitative review and test of its relations with task and contextual performance. Personnel Psychology, 64(1), 89-136.

Cohen-Charash, Y., \& Spector, P. E. (2001). The role of justice in organizations: A meta-analysis. Organizational Behavior and Human Decision Processes, 86(2), 278-321.

Cole, M. S., Bernerth, J. B., Walter, F., \& Holt, D. T. (2010). Organizational justice and individuals' withdrawal: Unlocking the influence of emotional exhaustion. Journal of Management Studies, 47, 367-390.

Cole, M. S., Walter, F., Bedeian, A. G., \& O’Boyle, E. H. (2012). Job burnout and employee engagement: A meta-analytic examination of construct proliferation. Journal of Management, 38(5), $1550-1581$.

Colquitt, J. A. (2001). On the dimensionality of organizational justice: A construct validation of a measure. Journal of Applied Psychology, 86(3), 386-400.

Colquitt, J. A., Conlon, D. E., Wesson, M. J., Porter, C. O. L. H., \& Yee Ng, K. (2001). Justice at the millennium: A meta-analytic review of 25 years of organizational justice research. Journal of Applied Psychology, 86(3), 425-445.
Colquitt, J. A., Scott, B. A., Judge, T. A., \& Shaw, J. C. (2006). Justice and personality: Using integrative theories to derive moderators of justice effects. Organizational Behavior and Human Decision Processes, 100(1), 110-127.

Conway, J., \& Lance, C. (2010). What reviewers should expect from authors regarding common method bias in organizational research. Journal of Business and Psychology, 25(3), 325-334.

Cooper, W. H., \& Withey, M. J. (2009). The strong situation hypothesis. Personality \& Social Psychology Review, 13(1), $62-72$.

Crawshaw, J. R., van Dick, R., \& Brodbeck, F. C. (2012). Opportunity, fair process and relationship value: career development as a driver of proactive work behaviour. Human Resource Management Journal, 22(1), 4-20.

Cropanzano, R., Byrne, Z. S., Bobocel, D. R., \& Rupp, D. E. (2001). Moral virtues, fairness heuristics, social entities, and other denizens of organizational justice. Journal of Vocational Behavior, 58(2), 164-209.

Cropanzano, R., Goldman, B., \& Folger, R. (2003). Deontic justice: the role of moral principles in workplace fairness. Journal of Organizational Behavior, 24(8), 1019-1024.

Cropanzano, R., Li, A., \& Benson, L. (2011). Peer justice and teamwork process. Group \& Organization Management, 36(5), 567-596.

Das, D., Dharwadkar, R., \& Brandes, P. (2008). The importance of being 'Indian': Identity centrality and work outcomes in an offshored call center in India. Human Relations, 61(11), 1499-1530.

De Cremer, D., Brebels, L., \& Sedikides, C. (2008). Being uncertain about what? Procedural fairness effects as a function of general uncertainty and belongingness uncertainty. Journal of Experimental Social Psychology, 44(6), 1520-1525.

El Akremi, A., Vandenberghe, C., \& Camerman, J. (2010). The role of justice and social exchange relationships in workplace deviance: Test of a mediated model. Human Relations, 63(11), 1687-1717.

Evans, M. G. (1985). A Monte Carlo study of the effects of correlated method variance in moderated multiple regression analysis. Organizational Behavior and Human Decision Processes, 36(3), 305-323.

Fenton, N. E., \& Inglis, S. (2007). A critical perspective on organizational values. Nonprofit Management \& Leadership Journal, 17(3), 335-347.

Folger, R., \& Cropanzano, R. (2001). Fairness theory: Justice as accountability. In I. J. Greenberg \& R. Cropanzano (Eds.), Advances in organizational justice (pp. 89-118). Stanford, CA: Stanford University Press.

Fornell, C., \& Larcker, D. F. (1981). Evaluating structural equation models with unobservable variables and measurement error. Journal of Marketing Research, 18(1), 39-50.

Fortin, M., \& Fellenz, M. (2008). Hypocrisies of fairness: Towards a more reflexive ethical base in organizational justice research and practice. Journal of Business Ethics, 78(3), 415-433.

Fuller, J. B., Hester, K., Barnett, T., Frey, L., Relyea, C., \& Beu, D. (2006). Perceived external prestige and internal respect: New insights into the organizational identification process. Human Relations, 59, 815-846.

Giessner, S. R. (2011). Is the merger necessary? The interactive effect of perceived necessity and sense of continuity on post-merger identification. Human Relations, 64(8), 1079-1098.

Hakanen, J. J., Perhoniemi, R., \& Toppinen-Tanner, S. (2008). Positive gain spirals at work: From job resources to work engagement, personal initiative and work-unit innovativeness. Journal of Vocational Behavior, 73(1), 78-91.

Halbesleben, J. R. B., Harvey, J., \& Bolino, M. C. (2009). Too engaged? A conservation of resources view of the relationship 
between work engagement and work interference with family. Journal of Applied Psychology, 94(6), 1452-1465.

Harter, J. K., Schmidt, F. L., \& Hayes, T. L. (2002). Business-unitlevel relationship Between employee satisfaction, employee engagement, and business outcomes: A meta-analysis. Journal of Applied Psychology, 87(2), 268-279.

He, H., \& Brown, A. D., (2013). Organizational identity and organizational identification. A review of the literature and suggestions for future research. Group \& Organization Management, 38(1), 3-35.

Ho, V. T., Wong, S.-S., \& Lee, C. H. (2011). A tale of passion: Linking job passion and cognitive engagement to employee work performance. Journal of Management Studies, 48(1), 26-47.

Holmvall, C. M., \& Bobocel, D. R. (2008). What fair procedures say about me: Self-construals and reactions to procedural fairness. Organizational Behavior and Human Decision Processes, 105(2), 147-168.

Hooper, D., Coughlan, J., \& Mullen, M. R. (2008). Structural equation modeling: Guidelines for determining model fit. The Electronic Journal of Business Research Methods, 6(1), 53-60.

Hu, L. T., \& Bentler, P. M. (1999). Cutoff criteria for fit indexes in covariance structure analysis: Conventional criteria versus new alternatives. Structural Equation Modeling, 6(1), 1-55.

Iacobucci, D., Saldanha, N., \& Deng, X. (2007). A meditation on mediation: Evidence that structural equations models perform better than regressions. Journal of Consumer Psychology, 17(2), 139-153.

Kahn, W. A. (1990). Psychological conditions of personal engagement and disengagement at work. The Academy of Management Journal, 33(4), 692-724.

Kahn, W. A. (1992). To be fully there: Psychological presence at work. Human Relations, 45(4), 321-349.

Kim, H.-R., Lee, M., Lee, H.-T., \& Kim, N.-M. (2010). Corporate social responsibility and employee-company identification. Journal of Business Ethics, 95(4), 557-569.

Klein, K. J., Knight, A. P., Ziegert, J. C., Lim, B. C., \& Saltz, J. L. (2011). When team members' values differ: The moderating role of team leadership. Organizational Behavior and Human Decision Processes, 114(1), 25-36.

Konovsky, M. A. (2000). Understanding procedural justice and its impact on business organizations. Journal of Management, 26(3), 489-511.

Konovsky, M. A., \& Pugh, S. D. (1994). Citizenship behavior and social exchange. The Academy of Management Journal, 37(3), 656-669.

Li, A., \& Cropanzano, R. (2009). Do East Asians respond more/less strongly to organizational justice than North Americans? A meta-analysis. Journal of Management Studies, 46, 787-805.

Lind, E. A., Kulik, C. T., Ambrose, M., \& de vera Park, M. V. (1993). Individual and corporate dispute resolution: Using procedural fairness as a decision heuristic. Administrative Science Ouarterly, 38(2), 22-251.

Lind, E. A., \& Tyler, T. R. (1988). The social psychology of procedural justice. New York: Plenum Press.

Loi, R., Lam, L., \& Chan, K. (2012). Coping with Job Insecurity: The role of procedural justice, ethical leadership and power distance orientation. Journal of Business Ethics, 108(3), 361-372.

Luyckx, K., Duriez, B., Klimstra, T. A., \& De Witte, H. (2010). Identity statuses in young adult employees: Prospective relations with work engagement and burnout. Journal of Vocational Behavior, 77(3), 339-349.

MacCallum, R. C., Browne, M. W., \& Sugarawa, H. M. (1996). Power analysis and determination of sample size for covariance structure modelling. Psychological Methods, 1(2), 130-149.

MacKinnon, D. P., Lockwood, C. M., \& Williams, J. (2004). Confidence limits for the indirect effect: Distribution of the product and resampling methods. Multivariate Behavioral Research, 39(1), 99-128.
Macleod, D., \& Clarke, N. (2009). Engaging for success: Enhancing performance thorough employee engagement. Retrieved June 20, 2012 from http://www.bis.gov.uk/policies/employment-matters/ strategies/employee-engagement.

Mael, F. A., \& Ashforth, B. E. (1992). Alumni and their alma mater: A partial test of the reformulated model of organizational identification. Journal of Organizational Behvaiour, 13, 103-123.

Mayer, D., Aquino, K., Greenbaum, R. L., \& Kuenzi, M. (2012). Who displays ethical leadership, and why does it matter? An examination of antecedents and consequences of ethical leadership. Academy of Management Journal, 55(1), 151-171.

McFerran, B., Aquino, K., \& Duffy, M. (2010). Individual predictors of the commitment to integrity: The Role of Personality and Moral Identity. Business Ethics Quarterly, 20, 35-56.

Meyer, R. D., Dalal, R. S., \& Bonaccio, S. (2009). A meta-analytic investigation into the moderating effects of situational strength on the conscientiousness-performance relationship. Journal of Organizational Behavior, 30(8), 1077-1102.

Meyer, R. D., Dalal, R. S., \& Hermida, R. (2010). A review and synthesis of situational strength in the organizational sciences. Journal of Management, 36(1), 121-140.

Meyer, R. D., Dalal, R. S., José, I. J., Hermida, R., Chen, T. R., Vega, R. P., et al. (2011). Measuring job-related situational strength and assessing its interactive effects with personality on voluntary work behavior. Journal of Management. doi:10.1177/0149206311425613.

Mischel, W. (1977). The interaction of person and situation. In D. Magnusson \& N. S. Endler (Eds.), Personality at the crossroads: Current issues in interactional psychology (pp. 333-352). Hillsdale, NJ: Laurence Earlbaum Associates.

Mullins, J. W., \& Cummings, L. L. (1999). Situational strength-A framework for understanding the role of individuals in initiating proactive strategic change. Journal of Organizational Change Management, 12(6), 462-479.

Muthen, L. K., \& Muthen, B. O. (1998-2010). Mplus user's guide (5th ed.). Los Angeles, CA: Muthen \& Muthen.

Olkkonen, M.-E., \& Lipponen, J. (2006). Relationships between organizational justice, identification with organization and work unit, and group-related outcomes. Organizational Behavior and Human Decision Processes, 100(2), 202-215.

Organization, Gallup. (2010). Employee engagement: What's your engagement ratio?. Washington, DC: The Gallup Organization.

Parker, S. L., Jimmieson, N. L., \& Amiot, C. E. (2010). Selfdetermination as a moderator of demands and control: Implications for employee strain and engagement. Journal of Vocational Behavior, 76(1), 52-67.

Reed, A, I. I., Aquino, K., \& Levy, E. (2007). Moral identity and judgments of charitable behaviors. Journal of Marketing, 71(1), 178-193.

Restubog, S. L. D., Hornsey, M. J., Bordia, P., \& Esposo, S. R. (2008). Effects of psychological contract breach on organizational citizenship behaviour: Insights from the group value model. Journal of Management Studies, 45(8), 1377-1400.

Reynolds, S. J., \& Ceranic, T. L. (2007). The effects of moral judgment and moral identity on moral behavior: An empirical examination of the moral individual. Journal of Applied Psychology, 92, 1610-1624.

Rich, B. L., Lepine, J. A., \& Crawford, E. R. (2010). Job engagement: Antecedents and effects on job performance. Academy of Management Journal, 53, 617-635.

Rupp, D., \& Bell, C. (2010). Retribution, moral self regulation and self interest in the decision to punish: A moral motives extension of the deontic model of justice. Business Ethics Quarterly, 20, 89-106.

Rupp, D. E., \& Cropanzano, R. (2002). The mediating effects of social exchange relationships in predicting workplace outcomes from multifoci organizational justice. Organizational Behavior and Human Decision Processes, 89(1), 925-946. 
Sedikides, C., Hart, C. M., \& De Cremer, D. (2008). The self in procedural fairness. Social and Personality Psychology Compass, 2(6), 2107-2124.

Shane, S. A., Herold, D. M., \& House, R. J. (1996). Situational determinism-One step forward, two steps back? Academy of Management Review, 21(2), 343-345.

Shao, R., Aquino, K., \& Freeman, D. (2008). Beyond moral reasoning: A review of moral identity research and its implications for business ethics. Business Ethics Quarterly, 18, 513-540.

Shavitt, S., Torelli, C. J., \& Wong, J. (2009). Identity-based motivation: Constraints and opportunities in consumer research. Journal of Consumer Psychology, 19(3), 261-266.

Sherman, R. A., Nave, C. S., \& Funder, D. C. (2010). Situational similarity and personality predict behavioral consistency. Journal of Personality and Social Psychology, 99(2), 330-343.

Siemsen, E., Roth, A., \& Oliveira, P. (2010). Common method bias in regression models with linear, quadratic, and interaction effects. Organizational Research Methods, 13(3), 456-476.

Simpson, M. R. (2009). Engagement at work: A review of the literature. International Journal of Nursing Studies, 46(7), 1012-1024.

Skarlicki, D. P., \& Folger, R. (1997). Retaliation in the workplace: The roles of distributive, procedural, and interactional justice. Journal of Applied Psychology, 82(3), 434-443.

Skarlicki, D. P., Van Jaarsveld, D. D., \& Walker, D. D. (2008). Getting even for customer mistreatment: The role of moral identity in the relationship between customer interpersonal injustice and employee sabotage. Journal of Applied Psychology, 93, 1335-1347.

Sluss, D. M., \& Ashforth, B. E. (2008). How relational and organizational identification converge: Processes and conditions. Organizational Science, 19(6), 807-823.

Sluss, D. M., \& Ashworth, B. E. (2007). Relational identity and identification: Defining ourselves through work relationships. Academy of Management Review, 32(1), 9-32.

Swann, W. B., Griffin, J. J., Predmore, S. C., \& Gaines, B. (1987). The cognitive-affective crossfire: When self-consistency confronts self-enhancement. Journal of Personality and Social Psychology, 52(5), 881-889.

Tajfel, H. (1981). Human groups and social categories: Studies in social psychology. Cambridge: Cambridge University Press.

Tett, R. P., \& Burnett, D. D. (2003). A personality trait-based interactionist model of job performance. Journal of Applied Psychology, 88(3), 500-517.

Treviño, L. K. (1986). Ethical decision making in organizations: A person-situation interactionist model. Academy of Management Review, 11(3), 601-617.

Treviño, L. K., den Nieuwenboer, N. A., \& Kish-Gephart, J. J. (Un)ethical behavior in organizations. Annual Review of Psychology (forthcoming).
Treviño, L. K., Weaver, G. R., \& Reynolds, S. J. (2006). Behavioral ethics in organizations: A review. Journal of Management, 32(6), 951-990.

Truss, C., Soane, E., Edwards, C., Wisdom, K., Croll, A., \& Burnett, J. (2006). Working Life: Employee attitudes and engagement, 2006. London: CIPD.

Turner, J. C., Hogg, M. A., Oakes, P. J., Reicher, S. D., \& Wetherell, M. S. (1987). Rediscovering the social group: A self categorization theory. Oxford: Blackwell.

Tyler, T. R. (2000). Social justice: Outcome and procedure. International Journal of Psychology, 35(2), 117-125.

Tyler, T. R., \& Blader, S. L. (2003). The group engagement model: Procedural justice, social identity, and cooperative behavior. Personality and Social Psychology Review, 7(4), 349-361.

Tyler, T., Degoey, P., \& Smith, H. (1996). Understanding why the justice of group procedures matters: A test of the psychological dynamics of the group-value model. Journal of Personality and Social Psychology, 70(5), 913-930.

Vitell, S., Bing, M., Davison, H., Ammeter, A., Garner, B., \& Novicevic, M. (2009). Religiosity and moral identity: The mediating role of self-control. Journal of Business Ethics, 88, 601-613.

Walumbwa, F. O., Cropanzano, R., \& Hartnell, C. A. (2009). Organizational justice, voluntary learning behavior, and job performance: A test of the mediating effects of identification and leader-member exchange. Journal of Organizational Behavior, $30(8), 1103-1126$.

Weaver, G. R. (2006). Virtue in organizations: Moral identity as a foundation for moral agency. Organization Studies, 27, 341-368.

Winterich, K., Mittal, V., \& Ross, W, Jr. (2009). Donation behavior toward in-groups and out-groups: The role of gender and moral identity. Journal of Consumer Research, 36, 199.

Wu, P.-C., \& Chaturvedi, S. (2009). The role of procedural justice and power distance in the relationship between high performance work systems and employee attitudes: A multilevel perspective. Journal of Management, 35(5), 1228-1247.

Xanthopoulou, D., Bakker, A. B., Demerouti, E., \& Schaufeli, W. B. (2009). Reciprocal relationships between job resources, personal resources, and work engagement. Journal of Vocational Behavior, 74(3), 235-244.

Zapata-Phelan, C. P., Colquitt, J. A., Scott, B. A., \& Livingston, B. (2009). Procedural justice, interactional justice, and task performance: The mediating role of intrinsic motivation. Organizational Behavior and Human Decision Processes, 108(1), 93-105.

Zhu, W., Riggio, R. E., Avolio, B. J., \& Sosik, J. J. (2011). The effect of leadership on follower moral identity: Does transformational/ transactional style make a difference? Journal of Leadership \& Organizational Studies, 18(2), 150-163. 